\title{
Size-Dependent Cytotoxicity and Reactive Oxygen Species of Cerium Oxide Nanoparticles in Human Retinal Pigment Epithelia Cells
}

\author{
Yuanyuan $\mathrm{Ma}^{\mathrm{I}, *}$ \\ Peng $\mathrm{Li}^{2}, *$ \\ Laien Zhao' \\ Jia Liu' \\ Jinguo $\mathrm{Yu}^{3}$ \\ Yanmei Huang' \\ Yuting Zhu' \\ Zelin $\mathrm{Li}^{\prime}$ \\ Ruikang Zhao' \\ Shaofeng Hua' \\ Yanping Zhu' \\ Zhuhong Zhang'
}

'School of Pharmacy, Key Laboratory of Molecular Pharmacology and Drug Evaluation (Yantai University), Ministry of Education, Collaborative Innovation Center of Advanced Drug Delivery System and Biotech Drugs in Universities of Shandong, Yantai University, Yantai, 264005, People's Republic of China; ${ }^{2}$ Department of Nephrology Yantai Yuhuangding Hospital, Qingdao University, Yantai, 264005, Shandong, People's Republic of China; ${ }^{3}$ Department of Ophthalmology, Tianjin Medical University General Hospital, Tianjin, 300052, People's Republic of China

*These authors contributed equally to this work
Correspondence: Zhuhong Zhang School of Pharmacy, Yantai University, 30 Qingquan Road, Yantai, Shandong Province, 264005, People's Republic of China

Tel +86 I852685I69|

Email zhzhang0608@ytu.edu.cn
Purpose: The use of cerium oxide nanoparticles $\left(\mathrm{CeO}_{2} \mathrm{NPs}\right)$, a lanthanide element oxide and bivalent compound, has been growing continuously in industry and biomedicine. Due to their wide application, the potential human health problems of $\mathrm{CeO}_{2} \mathrm{NPs}$ have attracted attention, but studies on the toxicity of this compound to human eyes are lacking. This study investigated the cytotoxicity and reactive oxygen species (ROS) of $\mathrm{CeO}_{2} \mathrm{NPs}$ in human retinal pigment epithelial cells (ARPE-19 cells).

Methods: Using the transmission electron microscope (TEM), the size distribution and shape of $\mathrm{CeO}_{2} \mathrm{NPs}$ were characterized. To explore the effect of $\mathrm{CeO}_{2} \mathrm{NP}$ size on ophthalmic toxicity in vitro, three sizes $(15,30$ and $45 \mathrm{~nm})$ of $\mathrm{CeO}_{2}$ NPs were investigated using ATP content measurement, LDH release measurement and cell proliferation assay in ARPE-19 cells. ROS values and mitochondrial membrane potential depolarization were evaluated by $\mathrm{H}_{2}$ DCF-DA staining and JC-1 staining. Morphology changes were detected using a phase-contrast microscope.

Results: The cytotoxicity of $15 \mathrm{~nm} \mathrm{CeO}_{2} \mathrm{NPs}$ was found to be the highest and hence was further explored. Treatment with $15 \mathrm{~nm} \mathrm{CeO}_{2}$ NPs caused the morphology of ARPE-19 cells to change in a dose- and time-dependent manner. Moreover, the treatment induced excessive ROS generation and mitochondrial membrane potential depolarization. In addition, cytotoxicity was attenuated by the application of a ROS scavenger N-acetyl-L- cysteine (NAC).

Conclusion: $\mathrm{CeO}_{2}$ NPs induced cytotoxicity in ARPE-19 cells and excessive production of ROS and decreasing mitochondrial membrane potential. The Overproduction of ROS partially contributes to $\mathrm{CeO}_{2}$ NP-induced cytotoxicity.

Keywords: nanomaterials, ophthalmic toxicity, oxidative stress, mitochondrial membrane potential depolarization

\section{Introduction}

Nanomaterials have unique properties, such as small size and enlarged surface area, that enhance regenerative and catalytic enzyme activities and, consequently, their biological effects. Cerium (Ce), a critical rare earth element with a unique f-electron configuration that gives its compounds special properties, has been called a universal new material. ${ }^{1}$ In cerium oxide nanoparticles $\left(\mathrm{CeO}_{2} \mathrm{NPs}\right)$, there are two valence states- $\mathrm{Ce}^{3+}$ (reduced state) and $\mathrm{Ce}^{4+}$ (oxidation state) - and these two states can be converted to each other. The transition between $\mathrm{Ce}^{4+} / \mathrm{Ce}^{3+}$ on the crystal surface results in catalytic and antioxidant effects. ${ }^{1-3}$ Pezzini et al reported that $\mathrm{CeO}_{2}$ NPs serve as antioxidants in primary cultured skin fibroblasts. ${ }^{4}$ As free 
radical scavengers, $\mathrm{CeO}_{2}$ NPs can treat various diseases induced by oxidative stress. ${ }^{5}$ Recent studies have found that $\mathrm{CeO}_{2}$ NPs act as ROS scavengers in diabetic nephropathy, ${ }^{6}$ rheumatoid arthritis, ${ }^{7}$ and ischemic stroke. ${ }^{8}$ Furthermore, $\mathrm{CeO}_{2}$ NPs are widely used in single-phase or multiphase drug carriers or delivery devices to solve cancer drug resistance and mistargeting, and to achieve a synergistic anti-tumor activity with drugs. ${ }^{9-11}$ In addition, some studies have reported that $\mathrm{CeO}_{2} \mathrm{NPs}$ are used in the treatment of eye diseases, such as to reduce lightinduced retinal degeneration ${ }^{12}$ and photoreceptor death rate. ${ }^{13}$ Moreover, $\mathrm{CeO}_{2}$ NPs have been reported to act as antioxidants in the retina and protect against retinal nerve damage induced by high-intensity light exposure. ${ }^{14}$

Therefore, the widespread use of $\mathrm{CeO}_{2} \mathrm{NPs}$ has raised human health concerns. It has been suggested that $\mathrm{CeO}_{2}$ NPs lead to ROS generation, DNA damage, and apoptosis in human lung cells. ${ }^{15,16}$ Moreover, $\mathrm{CeO}_{2}$ NPs induce cytotoxicity of the human hepatoma cell line SMMC7721 through oxidative stress and activation of the MAPK signaling pathway. ${ }^{17}$ In addition, $\mathrm{CeO}_{2} \mathrm{NPs}$ induce cytotoxicity and oxidative stress in human skin keratinocytes $^{18}$ and genotoxicity in human intestinal Caco-2 cells. ${ }^{19}$ However, despite being an important and sensitive organ, the eyes have been ignored in evaluating the toxicity of $\mathrm{CeO}_{2} \mathrm{NPs}$; whether or not $\mathrm{CeO}_{2} \mathrm{NPs}$ exert toxicity to other organs is largely unknown.

ROS are natural byproducts of normal oxidative metabolism and of free radicals such as the highly reactive hydroxyl radical $(\cdot \mathrm{OH})$ or superoxide anion radical $\left(\mathrm{O}_{2} \cdot{ }^{-}\right) \cdot{ }^{20}$ ROS are unstable and highly reactive compounds that can strip electrons from nearby molecules and induce significant oxidative damage to cellular structures if the amount of ROS exceeds the system's antioxidant capacity. ${ }^{21,22}$ The cytotoxicity effect is referred to as "oxidative stress," which leads to a change in the mitochondrial membrane potential. ${ }^{23}$ In the whole life cycle of cells, mitochondria use oxidable substrates to produce an electrochemical proton gradient on the mitochondrial membrane, which is used to produce ATP and generate energy for cellular activities. ${ }^{24}$ The evaluation of the mitochondrial membrane potential $\left(\Delta_{\Psi \mathrm{m}}\right)$ of intact cells can provide the necessary information to assess their physiological and pathological status. ${ }^{25,26}$

This study evaluated the toxicity of $\mathrm{CeO}_{2}$ NPs with different particle sizes in ARPE-19 cells, which are a type of human retinal pigment epithelial cell. We also determined the role of $\mathrm{CeO}_{2} \mathrm{NPs}$ in ROS generation. In addition, we explored the change in mitochondrial membrane potential in response to $\mathrm{CeO}_{2}$ NPs treatment.

\section{Materials and Methods Chemical and Reagents}

$\mathrm{CeO}_{2}$ NPs were purchased from Shanghai Xiangtian Nanomaterials Co., Ltd. (Shanghai, China); fetal bovine serum (FBS), DME/F-12 medium, and penicillin/streptomycin were obtained from Life Technologies (Carlsbad, CA, USA); N-acetylcysteine (NAC), and 2',7'Dichlorofluorescin diacetate $\left(\mathrm{H}_{2} \mathrm{DCF}-\mathrm{DA}\right)$ were purchased from Sigma-Aldrich (St. Louis, MO, USA); and a mitochondrial membrane potential assay kit with JC-1 was purchased from Beyotime Biotechnology Co., Ltd. (Shanghai, China).

\section{Characterization of Different Sizes of $\mathrm{CeO}_{2} \mathrm{NPs}$}

The size and morphology of $\mathrm{CeO}_{2}$ NPs were examined using a transmission electron microscope (TEM). Briefly, a drop of $\mathrm{CeO}_{2}$ NPs suspension at $50 \mu \mathrm{g} / \mathrm{mL}$ was tested under a TEM (200 kV, Tecnai F20, Philips, The Netherlands).

\section{Cell Culture}

The human retinal pigment epithelial cell line (ARPE-19 cells) was from the $\mathrm{Fu}$ Heng Cell Center (Shanghai, China). It was cultured with $10 \% \mathrm{FBS}$, penicillin (50 U/ $\mathrm{mL})$, and streptomycin $\left(50 \mathrm{U} / \mathrm{mL}\right.$ at $37^{\circ} \mathrm{C}$ in a humidified atmosphere with $5 \% \mathrm{CO}_{2}$. Next, $\mathrm{CeO}_{2} \mathrm{NPs}$ were dispersed in ultrapure water to prepare stock solutions $(200 \mathrm{mg} / \mathrm{mL})$. The stock solution was sonicated using a probe sonicator (Ningbo Xinzhi Biotechnology Co., Ltd., China) at 600 $\mathrm{W}$ for $40 \mathrm{~min}$ and diluted to different concentrations with culture medium and penicillin/streptomycin just before cell exposure. The cells were adjusted to a concentration of $1 \times 10^{5}$ cells $/ \mathrm{mL}$ in a volume of $100 \mu \mathrm{L}$ per well in 96well plates for toxicity assays.

\section{Cell Morphology}

ARPE-19 cells were collected and seeded into 96-well plates at a density of $1 \times 10^{4}$ cells/well and cultured overnight in a $\mathrm{CO}_{2}$ incubator. Cells were exposed to $\mathrm{CeO}_{2} \mathrm{NPs}$ at different concentrations $(1-100 \mu \mathrm{g} / \mathrm{mL})$ for 24 and 48 h. The cell morphological changes were examined using a phase-contrast microscope (Leica DM16000B, Germany). 


\section{Cell Viability Assay}

The Cell Titer 96 Aqueous One Solution Cell Proliferation Assay (Promega Corporation, Madison, WI, USA) was employed to examine cell viability. Following 24 or 48 $\mathrm{h}$ of exposure to $\mathrm{CeO}_{2}$ NPs at various concentrations, 10 $\mu \mathrm{L}$ of cell titer agents was added to each well. The 96-well plate was incubated in an incubator for $2 \mathrm{~h}$. Absorbance was measured at $490 \mathrm{~nm}$ with the Synergy H4 Hybrid microplate reader (Bio Tek Instruments, Inc., Winowinsky, VT, USA).

\section{Measurement of Cellular ATP Levels and Lactate Dehydrogenase (LDH) Release}

Cell Titer-Glo ${ }^{\circledR}$ Luminescent Cell Viability Assay (Promega, Madison, WI, USA) was used to assess the ATP levels in $\mathrm{CeO}_{2}$ NPs-treated ARPE-19 cells according to the manufacturer's instructions. Luminescence was recorded using a Synergy H4 Hybrid microplate reader.

The cytotoxicity of $\mathrm{CeO}_{2} \mathrm{NPs}$ was examined using the LDH Release Assay (Beyotime, Beijing, China) as described previously. ${ }^{27}$

\section{Measurement of Intracellular ROS}

Intracellular ROS concentration was measured using the fluorescent dye $\mathrm{H}_{2}$ DCF-DA. ${ }^{27}$ Briefly, ARPE-19 cells were treated with $10 \mu \mathrm{M} \mathrm{H}_{2} \mathrm{DCF}-\mathrm{DA}$ for $30 \mathrm{~min}$ in the cell culture incubator. The cells were washed twice with PBS and then treated with $3.125-100 \mu \mathrm{g} / \mathrm{mL} \mathrm{CeO}_{2} \mathrm{NPs}$ in phenol-red-free medium. The cells were continuously incubated, and the fluorescence intensities were measured at $6,12,24$, and 48 h time points with a Synergy H4 Hybrid microplate reader. Meanwhile, the oxidation of $\mathrm{H}_{2}$ DCF-DA was detected using a confocal laser scanning microscope (Leica TCS SP5, Germany) at the 24- and 48-h time points.

\section{Detection of Mitochondrial Membrane Potential}

JC-1 Staining Kit (Beyotime, Beijing, China) was used to assess mitochondrial membrane potential changes. Cells were seeded on dishes at a density of $1 \times 10^{5} \mathrm{cell} / \mathrm{mL}$ and stored overnight. The cells were treated with different concentrations of $\mathrm{CeO}_{2} \mathrm{NPs}$ for 24 and $48 \mathrm{~h}$. At the end of treatment, cells were removed from the medium, washed three times with PBS, and then incubated with JC-1 staining kit $(20 \mu \mathrm{M})$ for $15 \mathrm{~min}$. The JC-1 staining solution was removed, and the cells were washed three times. PBS was added for imaging by confocal laser scanning microscopy (Leica TCS SP5, Germany).

\section{Statistical Analysis}

Results were presented as the mean \pm standard deviation (SD). Analyses were performed using Graph Pad Prism 6 (Graph Pad Software; La Jolla, CA, USA). Statistical significance was determined by one-way analysis of variance (ANOVA) followed by the Dunnett's tests for comparisons between different concentrations to vehicle control or twoway ANOVA followed by the Sidak's multiple comparisons test for comparisons of two treatment groups in NAC pretreatment experiments. The differences were considered statistically significant when the $\mathrm{p}$ value was $<0.05$.

\section{Results}

\section{Characterization of $\mathrm{CeO}_{2} \mathrm{NPs}$}

The TEM images of the different sizes of $\mathrm{CeO}_{2}$ NPs are presented in Figure 1. The images showed that the average sizes of $\mathrm{CeO}_{2} \mathrm{NPs}$ were about $15 \pm 5 \mathrm{~nm}, 30 \pm 5 \mathrm{~nm}$, and $45 \pm 5 \mathrm{~nm}$ (Figure 1A-C, left panels). The enlarge images showed shapes of $\mathrm{CeO}_{2} \mathrm{NPs}$ were mostly irregular spheres (Figure $1 \mathrm{~A}-\mathrm{C}$, right panels).

\section{$15 \mathrm{~nm}$}

A

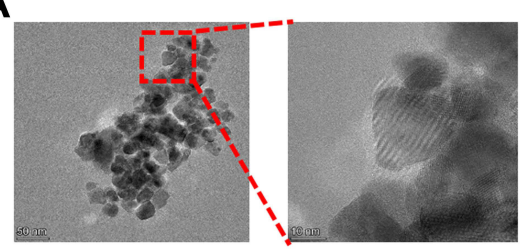

$30 \mathrm{~nm}$

B

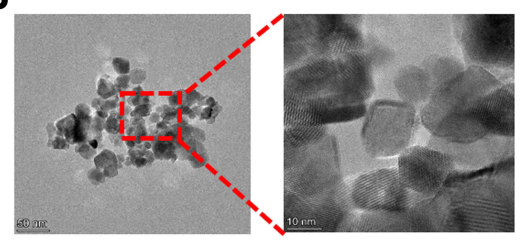

$45 \mathrm{~nm}$

C

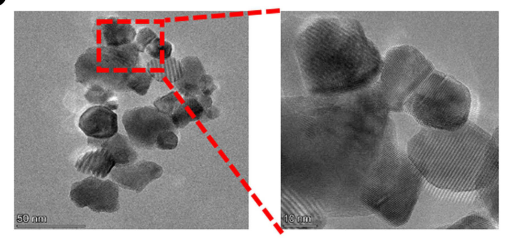

Figure I Characterization of $\mathrm{CeO}_{2} \mathrm{NPs}$ by transmission electron microscopy (TEM), showing nanoparticles with average diameters of $(\mathbf{A})$ I5 $\pm 5 \mathrm{~nm}$, (B) $30 \pm 5 \mathrm{~nm}$, and (C) $45 \pm 5 \mathrm{~nm}$. (Left image scale bar: $50 \mathrm{~nm}$ and right image scale bar: $10 \mathrm{~nm}$ ). 


\section{Cytotoxicity of $\mathrm{CeO}_{2}$ NPs in ARPE-19 Cells}

A previous study showed that $\mathrm{CeO}_{2} \mathrm{NPs}$ induced toxicity in human lung cells. ${ }^{16}$ In our present study using ARPE-19 cells we compared the cytotoxicity of $\mathrm{CeO}_{2} \mathrm{NPs}$ of different diameters, including 15, 30 and $45 \mathrm{~nm}$. The cytotoxicity was determined using three parameters, namely ATP content, LDH release and MTS viability assay (Figure 2). ARPE-19 cells were treated with different sizes of $\mathrm{CeO}_{2} \mathrm{NPs}$ at concentrations of $3.125 \mu \mathrm{g} / \mathrm{mL}$ to $100 \mu \mathrm{g} / \mathrm{mL}$ for 24 and 48 h. As shown in Figure $2 \mathrm{~A}$ and $\mathrm{B}, \mathrm{CeO}_{2}$ NPs caused a timedependent decrease in ATP content (Figure 2A and B). In addition, our results indicate that $\mathrm{CeO}_{2} \mathrm{NPs}$ lead to increased LDH release (Figure 2C and D) and growth inhibition (Figure 2E and F), and that ARPE-19 cells have the highest sensitivity to $15 \mathrm{~nm} \mathrm{CeO}{ }_{2}$ NPs. Therefore, in the current study, we focused the following studies on $15 \mathrm{~nm} \mathrm{CeO}_{2} \mathrm{NPs}$.

\section{$\mathrm{CeO}_{2} \mathrm{NPs}$ Induce Morphological Changes in Cells}

The morphology of ARPE-19 cells changed with the increase of $\mathrm{CeO}_{2} \mathrm{NP}$ concentration. Morphological analysis of ARPE-19 cells exposed to $\mathrm{CeO}_{2}$ NPs showed that the morphology of ARPE-19 cells became irregular starting from the concentration of $25 \mu \mathrm{g} / \mathrm{mL}$ after $24 \mathrm{~h}$ of exposure (Figure 3). At $48 \mathrm{~h}$, the changes of cell morphology became more prominent with increasing concentration. At $100 \mu \mathrm{g} /$ $\mathrm{mL}$, most cells detached, and the density was reduced.

\section{$\mathrm{CeO}_{2} \mathrm{NPs}$ Induce ROS Generation}

Cytotoxicity can result from ROS accumulation, so it is of interest to investigate whether $\mathrm{CeO}_{2}$ NPs induce ROS generation in human retinal pigment epithelial cells. Therefore, ARPE-19 cells were treated with $\mathrm{CeO}_{2} \mathrm{NPs}$ at concentrations ranging between $3.125 \mu \mathrm{g} / \mathrm{mL}$ and $100 \mu \mathrm{g} / \mathrm{mL}$, and ROS production was monitored at $6,12,24$ and 48 $\mathrm{h}$ (Figure 4A). ROS generation was observed as early as during the $12-\mathrm{h}$ treatment with $6.25 \mu \mathrm{g} / \mathrm{mL}$. The maximum ROS induction was two-fold that of the control at $24 \mathrm{~h}$ and $100 \mu \mathrm{g} / \mathrm{mL} \mathrm{CeO}_{2} \mathrm{NPs}$ treatment. At $48 \mathrm{~h}$, ROS levels were less remarkable compared to those at 12 and $24 \mathrm{~h}$ even though the production of ROS at $48 \mathrm{~h}$ remained significantly elevated compared to the corresponding control. For instance, at the concentration of $12.5 \mu \mathrm{g} / \mathrm{mL}$, ROS generation was 1.19-fold higher at $48 \mathrm{~h}$ for $\mathrm{CeO}_{2} \mathrm{NPs}$, whereas the ROS levels were 1.35-fold higher and 1.23-fold higher at 12 and $24 \mathrm{~h}$, respectively. The reduction in ROS may result from decreased cell viability (Figure 2). To further verify the ROS generation results, we performed ROS fluorescence staining. ARPE-19 cells were treated with $\mathrm{CeO}_{2} \mathrm{NPs}$ at concentrations of $6.25,25$ and $100 \mu \mathrm{g} / \mathrm{mL}$. Confocal laser scanning microscopy (CLSM) images showed that ROS levels increased (Figure 4B) as the incubation time increased. The increased intensity of the ROS indicator suggested that oxidative stress resulted from $\mathrm{CeO}_{2} \mathrm{NPs}$ treatment.

\section{$\mathrm{CeO}_{2} \mathrm{NPs}$ Induce Mitochondrial Dysfunction}

Mitochondrial dysfunction can lead to cellular energetic depression, which may result in cell death. In addition, mitochondria are the main sites of ATP and ROS generation. Mitochondrial depolarization (the $\Delta \Psi \mathrm{m}$ decrease) can lead to ROS accumulation and decreased ATP level. Next, we explored whether $\mathrm{CeO}_{2}$ NPs cause mitochondrial depolarization in ARPE-19 cells. The $\Delta \Psi \mathrm{m}$ was accessed by JC-1 dye; the accumulation of JC-1 in organelles leads to the formation of red J-aggregates (emission maximum at $590 \mathrm{~nm}$ ) at higher mitochondrial concentrations, reflecting higher mitochondrial potential, which, in addition to the typical green fluorescence of J-monomers (emission maximum of $529 \mathrm{~nm}$ ) at lower mitochondrial concentrations, indicates loss of membrane potential. The ARPE-19 cells were treated with $\mathrm{CeO}_{2} \mathrm{NPs}$ at concentrations of $6.25,25$ and $100 \mu \mathrm{g} / \mathrm{mL}$ for 24 and $48 \mathrm{~h}$. The decreased $\triangle \Psi$ m of ARPE-19 cells was observed as early as the 24-h treatment with $6.25 \mu \mathrm{g} / \mathrm{mL}$ (Figure $5 \mathrm{~A}$ ). JC-1 staining images showed that the transition from red fluorescence to green fluorescence became more obvious at $48 \mathrm{~h}$ (Figure 5B), which suggested that $\mathrm{CeO}_{2}$ NPs induced a significant timeand concentration-dependent decrease of $\Delta \Psi \mathrm{m}$.

\section{$\mathrm{CeO}_{2} \mathrm{NPs}$-Induced Cytotoxicity is Attenuated by the ROS Scavenger}

To investigate further the role of ROS generation in the cytotoxicity of $\mathrm{CeO}_{2} \mathrm{NPs}$, we used a ROS scavenger, NAC, to suppress intracellular ROS levels. Pretreating ARPE-19 cells with $10 \mathrm{mM} \mathrm{NAC}$ for $1 \mathrm{~h}$, prior to exposures of $3.125-100 \mu \mathrm{g} / \mathrm{mL} \mathrm{CeO}_{2} \mathrm{NPs}$ for $12 \mathrm{~h}$, significantly attenuated ROS induction and confirmed the effectiveness of NAC pretreatment (Figure 6A). The NAC pretreatment alleviated $\mathrm{CeO}_{2}$ NPs-induced cytotoxicity, as evidenced by reductions in both ATP content (Figure 6B) and LDH release (Figure 6C) in NAC pretreated groups. These results demonstrated that $\mathrm{CeO}_{2}$ NPs cytotoxicity was partially mediated by ROS generation. 
A

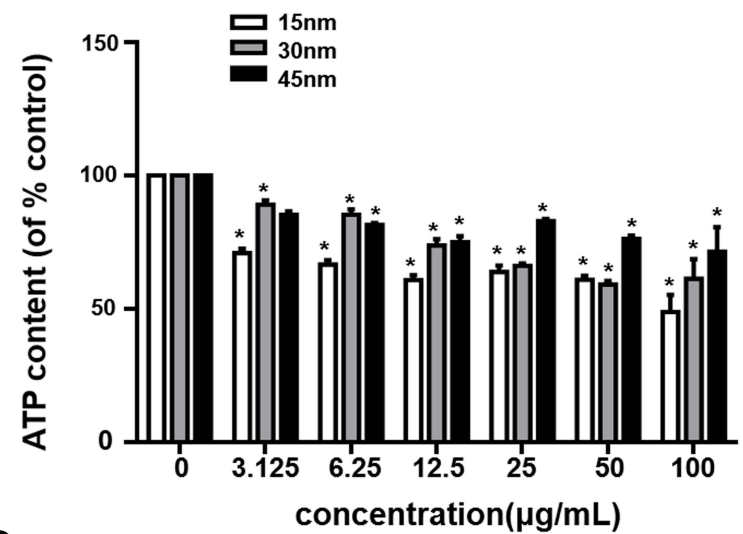

C

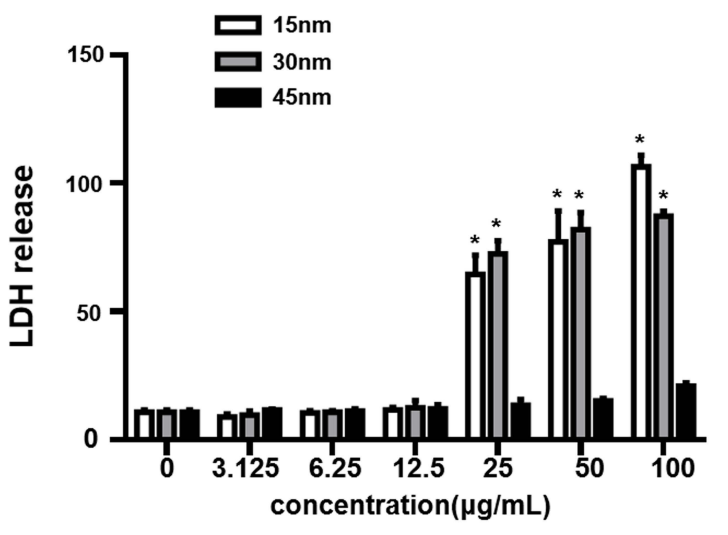

E

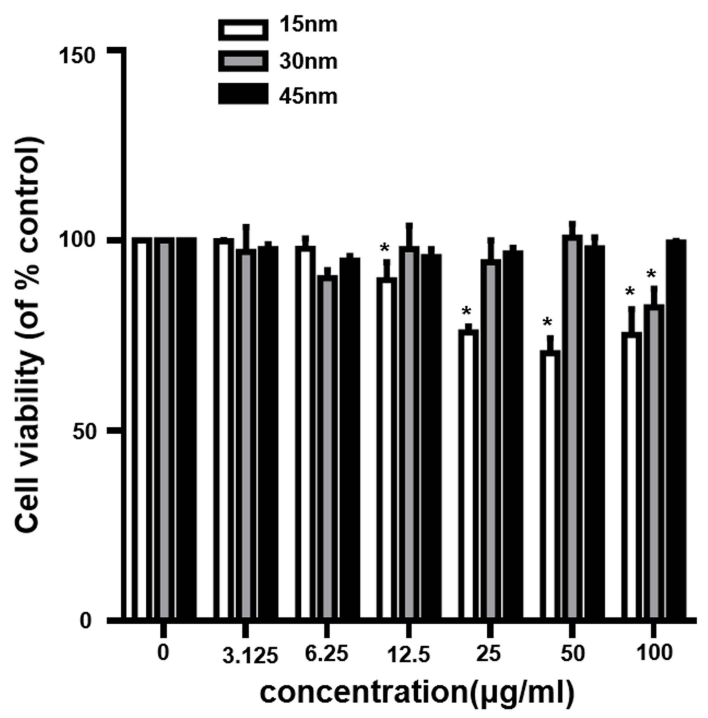

B
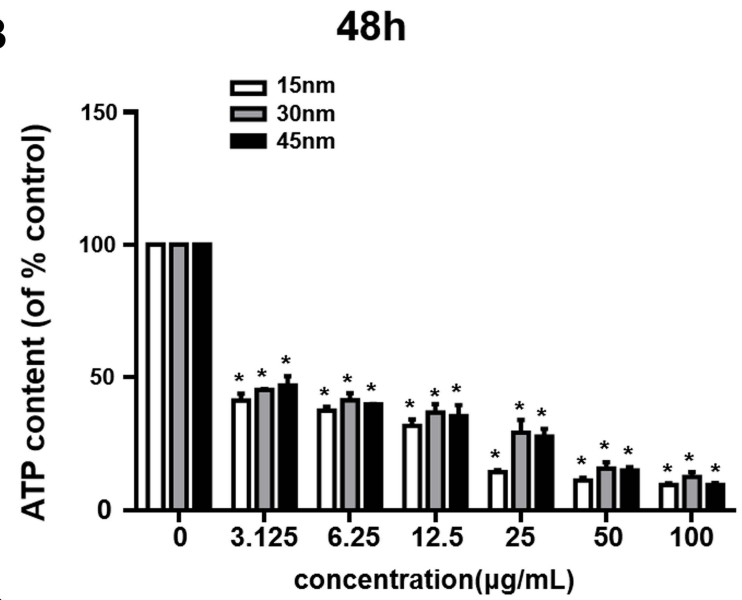

D

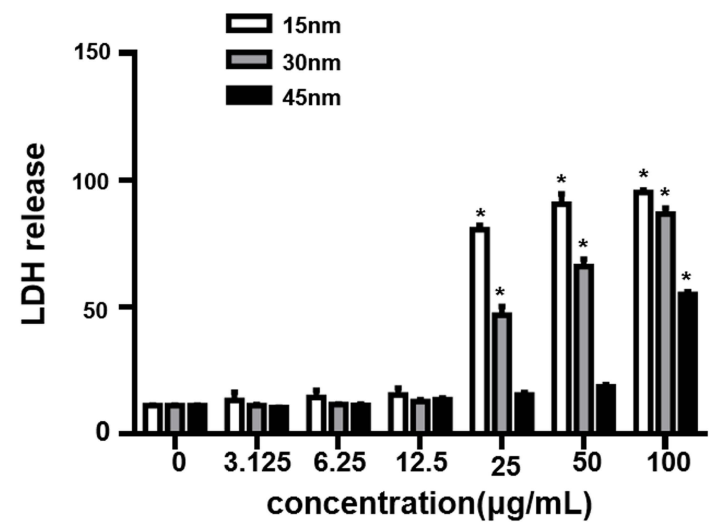

F

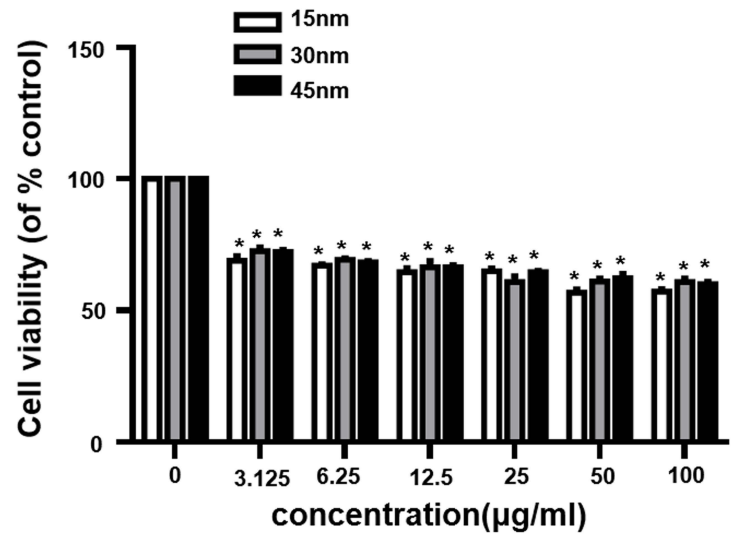

Figure $2 \mathrm{CeO}_{2} \mathrm{NPs}$ induced cytotoxicity in ARPE-19 cells. ARPE-19 cells were exposed to different concentrations $(3.125-100 \mu \mathrm{g} / \mathrm{mL})$ of $\mathrm{CeO} 2 \mathrm{NPs}$ for $(\mathbf{A}, \mathbf{C}$ and $\mathbf{E}) 24$ $\mathrm{h}$ and (B, D and F) $48 \mathrm{~h}$ before measurements of (A and B) ATP content, (C and D) LDH release and (E and F) cytotoxicity determined using the MTS assay. Data points represent the mean \pm SD from three independent experiments with three samples per concentration in each experiment. $* p<0.05$ compared to controls.

\section{Discussion}

Given the wide application of $\mathrm{CeO}_{2} \mathrm{NPs}$ in the biomedical field raises safety concerns for human health. The toxicity of $\mathrm{CeO}_{2}$ NPs has been studied previously by some investigator. $^{15,28,29}$ Characteristics of nanomaterials, including synthesis methodologies, size, and coating, affect their toxicity. ${ }^{30}$ Unfortunately, these previous studies ignored some of these characteristics on $\mathrm{CeO}_{2}$ NPs- 

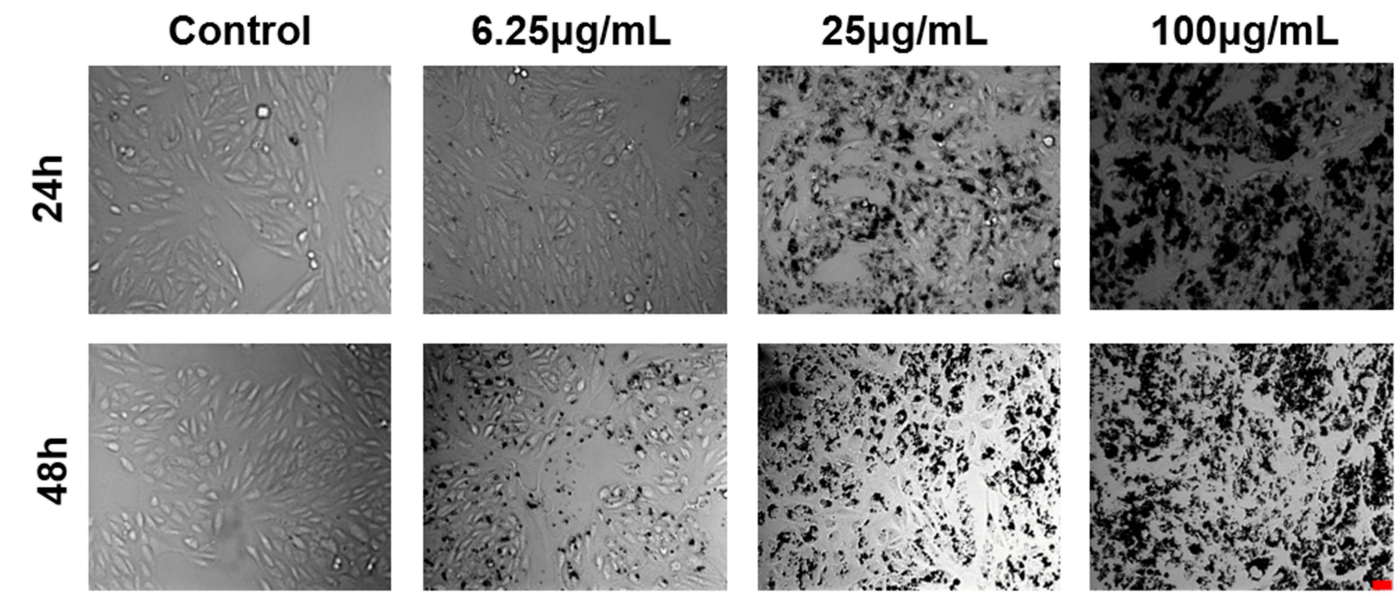

Figure $3 \mathrm{CeO}_{2} \mathrm{NPs}$ induced morphological changes in cells. Morphological changes of ARPE-19 cells were observed via microscopy following $24 \mathrm{~h}$ and $48 \mathrm{~h}$ of exposure to $\mathrm{CeO}_{2} \mathrm{NPs}$ with indicated concentrations. (Scale bar: $25 \mu \mathrm{m}$.).
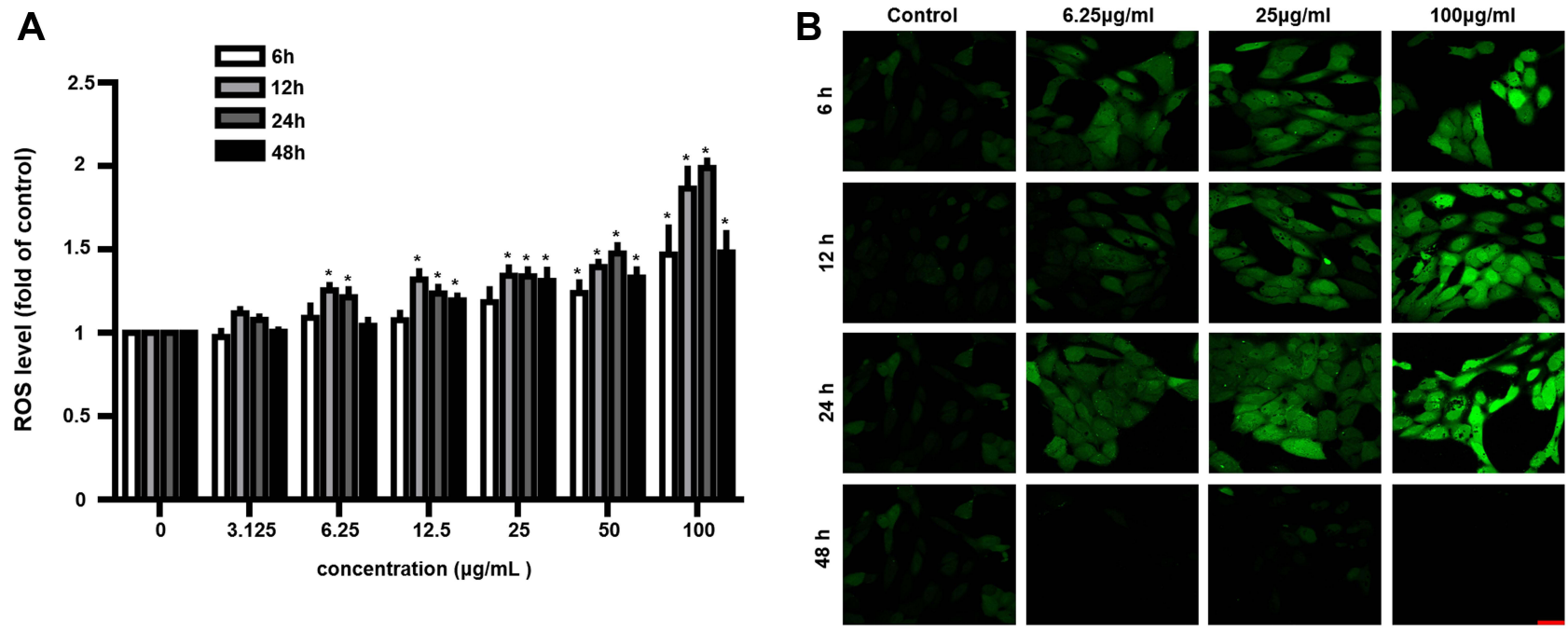

Figure $4 \mathrm{CeO}_{2} \mathrm{NPs}$ induced ROS generation. (A) ROS levels were measured at 6, I2, 24 and $48 \mathrm{~h}$ after exposure to various concentrations (3.I25-I00 $\left.\mu \mathrm{g} / \mathrm{mL}\right)$ of $\mathrm{CeO} 2$ $\mathrm{NPs}$ by $\mathrm{H}_{2}$ DCF-DA staining. (B) ROS levels were monitored under CLSM, which showed that ROS levels increased following 6, 12,24 , and $48 \mathrm{~h}$ of exposure to CeO $\mathrm{NPs}_{2}$ with concentrations of 25 and $100 \mu \mathrm{g} / \mathrm{mL}$. Data points represent the mean \pm SD from three independent experiments with three samples per concentration. ${ }^{*} p<0.05$ compared to controls. (Scale bar: $25 \mu \mathrm{m}$.).

induced cytotoxicity. In our present study, we investigated whether the size can affect the cytotoxicity of $\mathrm{CeO}_{2} \mathrm{NPs}$. We assessed the toxicity of $\mathrm{CeO}_{2} \mathrm{NPs}$ of different sizes $(15 \pm 5 \mathrm{~nm}, 30 \pm 5 \mathrm{~nm}$ and $45 \pm 5 \mathrm{~nm})$ in ARPE-19 cells. Lin et $\mathrm{al}^{16}$ and Mittal et $\mathrm{al}^{15}$ studied the fate of 20 and 177 $\mathrm{nm} \mathrm{CeO} 2$ NPs in human lung cells. They found that $\mathrm{CeO}_{2}$ NPs can induce oxidative stress, DNA damage and apoptosis in A549 cells. In SMMC-7721 cells, exposure to hexahedral $\mathrm{CeO}_{2}$ NPs with a size of 20-30 nm induced apoptosis and oxidative stress by activation of MAPK signaling pathways. ${ }^{17}$ Recently, the therapeutic effects of $\mathrm{CeO}_{2}$ NPs in the retinal degenerative process were reported. ${ }^{13,14}$ With the widespread application of $\mathrm{CeO}_{2}$ NPs to the treatment of ocular diseases, its ocular toxicity requires the attention of scientists and ophthalmologists. Therefore, we used ARPE-19 cells to study the ocular toxicity of $\mathrm{CeO}_{2}$ NPs.

Previous studies indicate that the size of nanoparticles significantly alters their toxicity potential. For example, AgNPs exhibit cytotoxicity and genotoxicity in a sizedependent manner in L5718Y cells. ${ }^{30}$ Kim et al studied the toxicity of silica nanoparticles with diameters of 20$200 \mathrm{~nm}$ in A549 epithelial cells, HepG2 epithelial cells and NIH/3T3 fibroblasts. They found that the cytotoxicity 
$24 h$

A
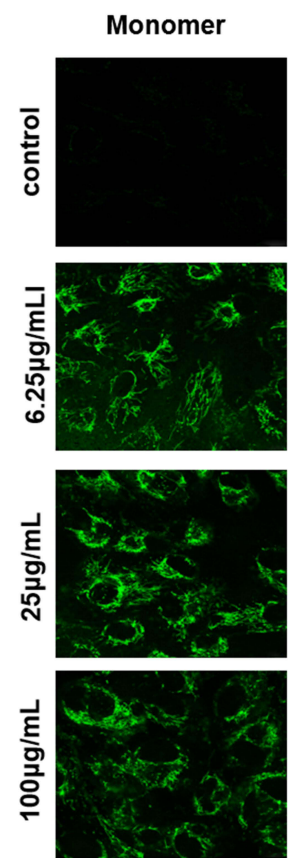
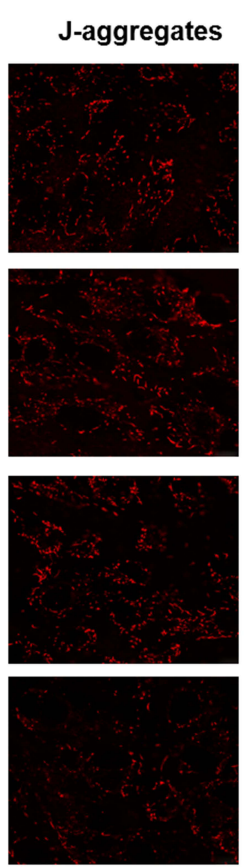
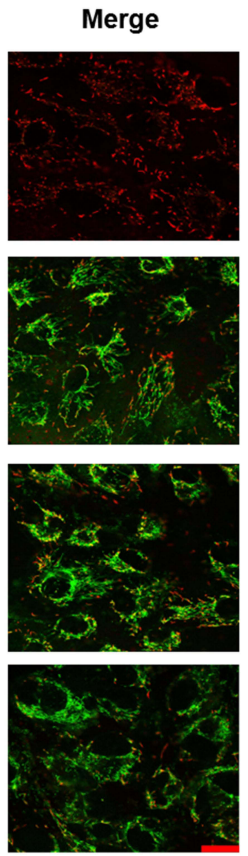

B

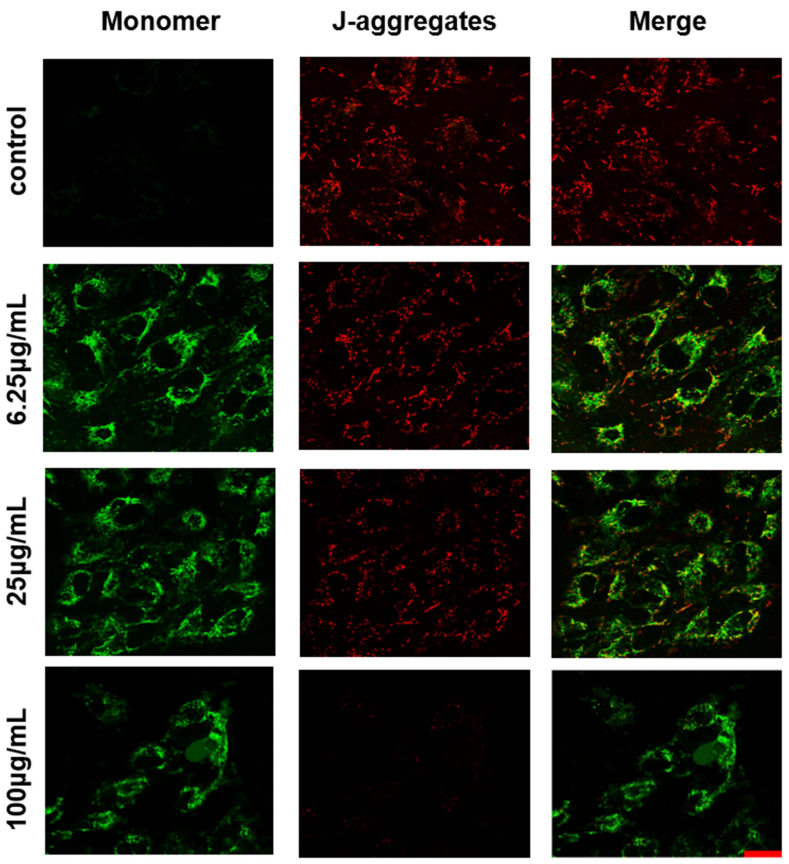

Figure $5 \mathrm{CeO}_{2} \mathrm{NPs}$ induce mitochondrial dysfunction. ARPE-19 cells were treated with three concentrations $(6.25,25$ and $100 \mu \mathrm{g} / \mathrm{mL})$ of $\mathrm{CeO} 2 \mathrm{NPs}$ for $24 \mathrm{~h}(\mathbf{A})$ and 48 h (B). JC-I staining was performed to assess mitochondrial membrane potential. (Scale bar: $25 \mu \mathrm{m}$.).

changed in a size-, dose- and cell type-dependent manner. ${ }^{31}$ Interestingly, among a group of silica nanoparticles ranging in size from 20 to $200 \mathrm{~nm}$, the $60 \mathrm{~nm}$ silica nanoparticles exhibited the highest toxicity. However, whether the toxicity of $\mathrm{CeO}_{2}$ NPs is size dependent has not been reported. In this study, we focused on the toxicity of $\mathrm{CeO}_{2}$ NPs of three sizes. First, the particle morphology and average size of $\mathrm{CeO}_{2}$ NPs were examined by TEM (Figure 1). The images showed three dimensions: $15 \pm 5$ $\mathrm{nm}, 30 \pm 5 \mathrm{~nm}$ and $45 \pm 5 \mathrm{~nm}$. Next, we compared the cytotoxicity of these three kinds of $\mathrm{CeO}_{2}$ NPs (Figure 2). All three of the tested $\mathrm{CeO}_{2}$ NPs induced different magnitudes of cytotoxicity in ARPE-19 cells. Among them, the $15 \mathrm{~nm} \mathrm{CeO}{ }_{2}$ NPs showed the highest cytotoxicity. Thus, in the subsequent toxicity studies, only $15 \mathrm{~nm} \mathrm{CeO}_{2} \mathrm{NPs}$ were used.

Mittal et al found that $8-20 \mathrm{~nm} \mathrm{CeO}_{2}$ NPs accumulated in the cytoplasm of A549 cells, resulting in cell morphology
A

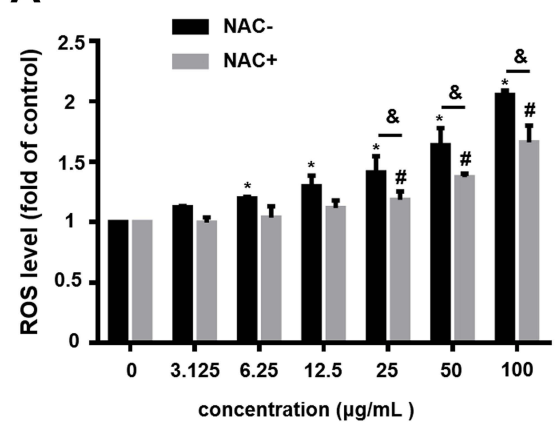

B

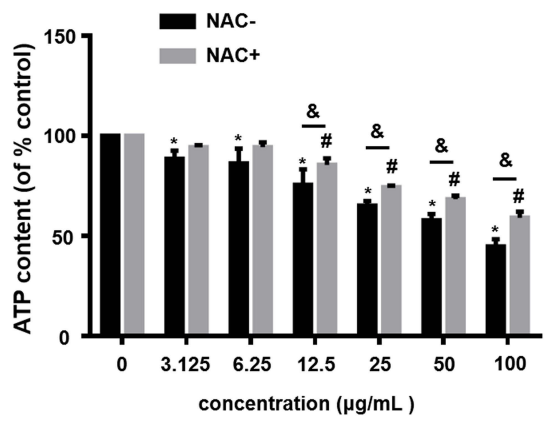

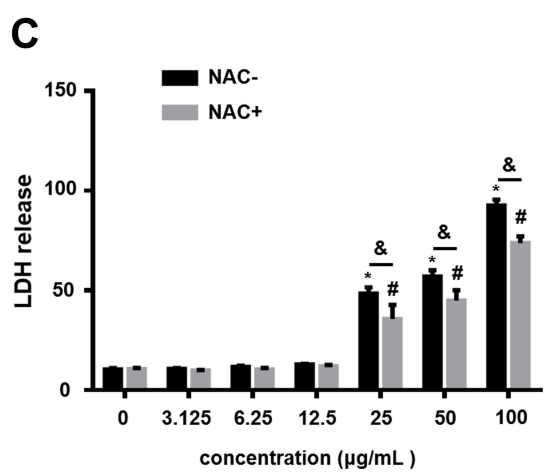

Figure $6 \mathrm{NAC}$ pretreatment alleviates $\mathrm{CeO}_{2}$ NPs-induced cytotoxicity. (A) Intracellular ROS levels were measured after a I2-h CeO $\mathrm{NPs}_{2}$ treatment with and without

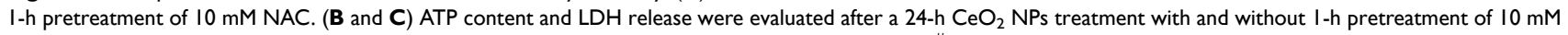
NAC. The data points represent the mean \pm SD from at least three independent experiments. ${ }^{*}, P<0.05$ compared to the vehicle control without or with $N A C$ pretreatment, respectively. ${ }^{\&} \mathrm{p}<0.05$ between the treatments with and without $\mathrm{NAC}$ pretreatment at the same concentration of $\mathrm{CeO}_{2} \mathrm{NPs}$ 
changes. ${ }^{15}$ We tested whether the cytotoxicity of $15 \mathrm{~nm} \mathrm{CeO} 2$ NPs affects the morphology of ARPE-19 cells. The density of ARPE-19 cells treated with $15 \mathrm{~nm} \mathrm{CeO}_{2}$ NPs became lower in a time- and concentration-dependent manner, and the shape of cells became ambiguous (Figure 3). In the past decade, $\mathrm{CeO}_{2}$ NPs have been reported as one kind of antioxidants for scavenging ROS in many diseases, ${ }^{32}$ including cancer, ${ }^{33}$ ocular diseases ${ }^{14}$ and neurodegenerative diseases. ${ }^{34}$ However, some studies reported that the small particle size and large reactive surface of nanomaterials can lead to toxicity through the production of ROS and oxidative stress. ${ }^{35,36}$ It has been reported that ROS accumulation is an upstream event that triggers cytotoxicity. ${ }^{37}$ Thus, we investigated whether $\mathrm{CeO}_{2}$ NPs induce ROS overproduction in ARPE19 cells. We found that ROS generation resulted from $\mathrm{CeO}_{2}$ NPs treatment and occurred at a lower concentration and earlier (Figures 4 and 6). Studies have reported ROS overproduction accompanied by mitochondrial membrane potential depolarization. ${ }^{15,38,39}$ In this study, $\mathrm{CeO}_{2}$ NPs exhibited the ability to induce mitochondrial dysfunction (Figure 5). The result suggested that the excessive production of ROS leads to mitochondrial dysfunction. Our previous study showed it is likely that ROS overproduction is the upstream event triggering cytotoxicity. ${ }^{37}$ In the present study, we confirmed this phenomenon also existed in the $\mathrm{CeO}_{2}$ NPsinduced cytotoxicity. This assertion was evidenced by the following assays: inhibition of ROS significantly diminished LDH release and cellular ATP depletion caused by $\mathrm{CeO}_{2} \mathrm{NPs}$ (Figure 6). It is worth noting that NAC only showed modest protective effect on $\mathrm{CeO}_{2}$ NPs-induced cytotoxicity (Figure 6B and $\mathrm{C}$ ); therefore, $\mathrm{CeO}_{2} \mathrm{NPs}$-induced ROS may not be the only cause of cytotoxicity.

\section{Conclusion}

In summary, the current study suggests that $\mathrm{CeO}_{2} \mathrm{NPs}$ induce morphological alteration and cytotoxicity in a time- and dose-dependent manner. Oxidative stress, including ROS overproduction and mitochondrial membrane potential depolarization, may be part of the cause of $\mathrm{CeO}_{2}$ NP-induced toxicity. Our results provide new insights into the toxicity of $\mathrm{CeO}_{2} \mathrm{NPs}$ in ophthalmologic research and improve our understanding of potential hazards associated with the application of $\mathrm{CeO}_{2} \mathrm{NPs}$ for treating eye diseases. However, this study did not explore molecular pathways related to the $\mathrm{CeO}_{2}$ NP-induced toxicity in ARPE-19 cells. For a better understanding of which signal pathways play a crucial role in $\mathrm{CeO}_{2} \mathrm{NP}$-induced ocular toxicity, additional studies are needed.

\section{Acknowledgment}

This work was supported by the National Natural Science Foundation of China (81970826 and 81500743), awarded to Zhuhong Zhang, and the Talent Induction Program for Youth Innovation Teams in Colleges and University of Shandong Province to Yanping Zhu.

\section{Author Contributions}

All authors made substantial contributions to conception and design, acquisition of data, or analysis and interpretation of data; took part in drafting the article or revising it critically for important intellectual content; agreed to submit to the current journal; gave final approval of the version to be published; and agree to be accountable for all aspects of the work.

\section{Disclosure}

The authors report no conflicts of interest in this work.

\section{References}

1. Celardo I, Pedersen JZ, Traversa E, Ghibelli LJN. Pharmacological potential of cerium oxide nanoparticles. Nanoscale. 2011;3 (4):1411-1420. doi:10.1039/c0nr00875c

2. Karakoti A, Singh S, Dowding JM, Seal S, Self WT. Redox-active radical scavenging nanomaterials. Chem Soc Rev. 2010;39 (11):4422-4432. doi:10.1039/b919677n

3. Ponnurangam S, O'Connell GD, Chernyshova IV, Wood K, Hung CT, Somasundaran P. Beneficial effects of cerium oxide nanoparticles in development of chondrocyte-seeded hydrogel constructs and cellular response to interleukin insults. Tissue Eng Part A. 2014;20(2122):2908-2919. doi:10.1089/ten.tea.2013.0592

4. Pezzini I, Marino A, Del Turco S, et al. Cerium oxide nanoparticles: the regenerative redox machine in bioenergetic imbalance. Nanomed. 2017;12(4):403. doi:10.2217/nnm-2016-0342

5. Casals E, Zeng M, Parra-Robert M, et al. Cerium oxide nanoparticles: advances in biodistribution, toxicity, and preclinical exploration. Small. 2020;16(20):e1907322. doi:10.1002/smll.201907322

6. Tong Y, Zhang L, Gong R, et al. A ROS-scavenging multifunctional nanoparticle for combinational therapy of diabetic nephropathy. Nanoscale. 2020;12(46):23607-23619. doi:10.1039/D0NR06098D

7. Kalashnikova I, Chung SJ, Nafiujjaman M, et al. Ceria-based nanotheranostic agent for rheumatoid arthritis. Theranostics. 2020;10(26):11863-11880. doi:10.7150/thno.49069

8. Kim CK, Kim T, Choi IY, et al. Ceria nanoparticles that can protect against ischemic stroke. Angew Chem Int Ed Engl. 2012;51 (44):11039-11043. doi:10.1002/anie.201203780

9. Gao R, Mitra RN, Zheng M, Wang K, Dahringer JC, Han Z. Developing nanoceria-based ph-dependent cancer-directed drug delivery system for retinoblastoma. Adv Funct Mater. 2018;28 (52):1806248. doi:10.1002/adfm.201806248

10. Muhammad F, Wang A, Qi W, Zhang S, Zhu G. Intracellular antioxidants dissolve man-made antioxidant nanoparticles: using redox vulnerability of nanoceria to develop a responsive drug delivery system. ACS Appl Mater Interfaces. 2014;6(21):19424-19433. doi:10.1021/am5055367

11. Zhang Y, Wu X, Hou C, et al. Dual-responsive dithio-polydopamine coated porous $\mathrm{CeO} 2$ nanorods for targeted and synergistic drug delivery. Int J Nanomed. 2018;13:2161-2173. doi:10.2147/IJN.S152002 
12. Tisi A, Passacantando M, Lozzi L, Maccarone R. Cerium oxide nanoparticles reduce the accumulation of autofluorescent deposits in light-induced retinal degeneration: insights for age-related macular de generation. Exp Eye Res. 2020;199:108169. doi:10.1016/j. exer.2020.108169

13. Wong LL, Pye QN, Lijuan C, Sudipta S, Mcginnis JF, Knut S. Defining the catalytic activity of nanoceria in the $\mathrm{P} 23 \mathrm{H}-1$ rat, a photoreceptor degeneration model. PLoS One. 2015;10(3): e0121977.

14. Tisi A, Passacantando M, Lozzi L, Riccitelli S, Bisti S, Maccarone R. Retinal long term neuroprotection by cerium oxide nanoparticles after an acute damage induced by high intensity light exposure. Exp Eye Res. 2019;182:30-38. doi:10.1016/j.exer.2019.03.003

15. Mittal S, Pandey AK. Cerium oxide nanoparticles induced toxicity in human lung cells: role of ROS mediated DNA damage and apoptosis. BioMed Res Int. 2014;2014:891934.

16. Lin W, Huang YW, Zhou XD, Ma YJ. Toxicity of cerium oxide nanoparticles in human lung cancer cells. Int $J$ Toxicol. 2006;25 (6):451-457. doi:10.1080/10915810600959543

17. Cheng G, Guo W, Han L, et al. Cerium oxide nanoparticles induce cytotoxicity in human hepatoma SMMC-7721 cells via oxidative stress and the activation of MAPK signaling pathways. Toxicol In Vitro. 2013;27(3):1082-1088. doi:10.1016/j.tiv.2013.02.005

18. Ngoc LTN, Bui VKH, Moon JY, Lee YC. In-vitro cytotoxicity and oxidative stress induced by cerium aminoclay and cerium oxide nanoparticles in human skin keratinocyte cells. J Nanosci Nanotechnol. 2019;19(10):6369-6375. doi:10.1166/jnn.2019.17035

19. Fisichella M, Berenguer F, Steinmetz G, Auffan M, Rose J, Prat O. Toxicity evaluation of manufactured $\mathrm{CeO} 2$ nanoparticles before and after alteration: combined physicochemical and whole-genome expression analysis in Caco-2 cells. BMC Genomics. 2014;15:700. doi:10.1186/1471-2164-15-700

20. Checa J, Aran JM. Reactive oxygen species: drivers of physiological and pathological processes. J Inflamm Res. 2020;13:1057-1073. doi:10.2147/JIR.S275595

21. Halliwell BJ. Oxidative stress and neurodegeneration: where are we now? J Neurochem. 2010;97(6):1634-1658.

22. Markovic Z, Trajkovic VJB. Biomedical potential of the reactive oxygen species generation and quenching by fullerenes (C60). Biomaterials. 2008;29(26):3561-3573. doi:10.1016/j.biomater ials.2008.05.005

23. Caputo F, De Nicola M, Sienkiewicz A, et al. Cerium oxide nanoparticles, combining antioxidant and UV shielding properties, prevent UV-induced cell damage and mutagenesis. J Nanoscale. 2015;7 (38):15643-15656. doi:10.1039/C5NR03767K

24. Logan A, Pell VR, Shaffer KJ, et al. Assessing the mitochondrial membrane potential in cells and in vivo using targeted click chemistry and mass spectrometry. Cell Metab. 2016;23(2):379-385. doi:10.1016/j.cmet.2015.11.014

25. Picard M, McEwen BS, Epel ES, Sandi C. An energetic view of stress: focus on mitochondria. Front Neuroendocrinol. 2018;49:72-85. doi:10.1016/j.yfrne.2018.01.001
26. Seppet E, Gruno M, Peetsalu A, et al. Mitochondria and energetic depression in cell pathophysiology. Int J Mol Sci. 2009;10 (5):2252-2303.

27. Zhang Z, Chen S, Mei H, et al. Ginkgo biloba leaf extract induces DNA damage by inhibiting topoisomerase II activity in human hepatic cells. Sci Rep. 2015;5:14633. doi:10.1038/srep14633

28. Balaji S, Mandal BK, Vinod Kumar Reddy L, Sen D. Biogenic ceria nanoparticles (CeO2 NPs) for effective photocatalytic and cytotoxic activity. Bioengineering. 2020;7(1):26. doi:10.3390/bioengin eering 7010026

29. Ahamed M, Akhtar MJ, Khan MAM, Alaizeri ZM, Alhadlaq HA. Evaluation of the cytotoxicity and oxidative stress response of CeO2-RGO nanocomposites in human lung epithelial A549 Cells. Nanomaterials. 2019;9(12):1709. doi:10.3390/nano9121709

30. Guo X, Li Y, Yan J, et al. Size- and coating-dependent cytotoxicity and genotoxicity of silver nanoparticles evaluated using in vitro standard assays. Nanotoxicology. 2016;10(9):1373-1384. doi:10.1080/17435390.2016.1214764

31. Kim IY, Joachim E, Choi H, Kim K. Toxicity of silica nanoparticles depends on size, dose, and cell type. Nanomedicine. 2015;11 (6):1407-1416. doi:10.1016/j.nano.2015.03.004

32. Das S, Dowding JM, Klump KE, McGinnis JF, Self W, Seal S. Cerium oxide nanoparticles: applications and prospects in nanomedicine. Nanomedicine. 2013;8(9):1483-1508. doi:10.2217/ nnm.13.133

33. Wason MS, Zhao J. Cerium oxide nanoparticles: potential applications for cancer and other diseases. Am J Transl Res. 2013;5 (2):126-131.

34. Kwon HJ, Cha MY, Kim D, et al. Mitochondria-targeting ceria nanoparticles as antioxidants for Alzheimer's disease. ACS Nano. 2016;10(2):2860-2870. doi:10.1021/acsnano.5b08045

35. Xia T, Kovochich M, Liong M, et al. Comparison of the mechanism of toxicity of zinc oxide and cerium oxide nanoparticles based on dissolution and oxidative stress properties. ACS Nano. 2008;2 (10):2121-2134. doi:10.1021/nn800511k

36. Nel A, Xia T, Madler L, Li N. Toxic potential of materials at the nanolevel. Science. 2006;311(5761):622-627. doi:10.1126/ science. 1114397

37. Zhang Z, Ren Z, Chen S, et al. ROS generation and JNK activation contribute to 4-methoxy-TEMPO-induced cytotoxicity, autophagy, and DNA damage in HepG2 cells. Arch Toxicol. 2018;92 (2):717-728. doi:10.1007/s00204-017-2084-9

38. Li L, Wang Y, Guo R, et al. Ginsenoside Rg3-loaded, reactive oxygen species-responsive polymeric nanoparticles for alleviating myocardial ischemia-reperfusion injury. $J$ Control Release. 2020;317:259-272. doi:10.1016/j.jconrel.2019.11.032

39. Guo X, Chen S, Zhang Z, et al. Reactive oxygen species and c-Jun N-terminal kinases contribute to TEMPO-induced apoptosis in L5178Y cells. Chem Biol Interact. 2015;235:27-36. doi:10.1016/j. cbi.2015.04.009
International Journal of Nanomedicine

\section{Publish your work in this journal}

The International Journal of Nanomedicine is an international, peerreviewed journal focusing on the application of nanotechnology in diagnostics, therapeutics, and drug delivery systems throughout the biomedical field. This journal is indexed on PubMed Central, MedLine, CAS, SciSearch ${ }^{\mathbb{R}}$, Current Contents ${ }^{\mathbb{B}} /$ Clinical Medicine,
Journal Citation Reports/Science Edition, EMBase, Scopus and the Elsevier Bibliographic databases. The manuscript management system is completely online and includes a very quick and fair peer-review system, which is all easy to use. Visit http://www.dovepress.com/ testimonials.php to read real quotes from published authors. 